\title{
OSCILLATION CONTROL OVER LIGHT DUTY CARS USING MAGNETIC SEMI-ACTIVE SHOCK ABSORBERS
}

\author{
István Zador ${ }^{1}$, Ádám Török ${ }^{2}$, István Vajda ${ }^{3}$, László Palkovics ${ }^{4}$ \\ ${ }^{1}$ Kogát Ltd., H-4400 Nyíregyháza, Hungary \\ 2, ${ }^{3}$ Budapest University of Technology and Economics, H-1111 Budapest, Hungary \\ ${ }^{4}$ Knorr-Bremse Hungary Ltd., H-6000 Kecskemét, Hungary \\ E-mails: ${ }^{1}$ zadoristvan@gmx.de; ${ }^{2}$ atorok@kgazd.bme.hu (corresponding author); \\ 3vajda@supertech.hu; ${ }^{4}$ laszlo.palkovics@knorr-bremse.com
}

Received 30 October 2010; accepted 5 July 2011

\begin{abstract}
The present vehicles on the road are equipped with an extended range of actuators, sensors and software controlling dynamics. It is still a difficult problem to solve for a suspension system simultaneously holding the body of the car in comfort and executing requirements imposed for other safety systems like ABS, ESP, steer-by-wire etc. Passive suspension systems are unlikely to provide a solution, and therefore the introduction of semi-active suspensions in practical use is necessary. A possible solution could be a permanent magnetic (PM) synchronous tube generator that can operate as a controllable shock absorber parallel with energy recuperative operation. Design software is realized to calculate geometrical and electrical parameters for arbitrary vehicle suspension systems.
\end{abstract}

Keywords: shock absorber, road vehicle suspension, permanent magnet, synchronous tube generator, energy recuperation, FEM simulation, design software.

\section{Introduction}

Environmentally friendly transportation is not only a key issue in Europe. R\&D investments have been made worldwide to decrease fuel consumption and lower emission. Some of researches are aimed at reducing emission using alternative fuels such as liquid biofuel mixtures (Török 2009; Raslavičius, Bazaras 2009; Matijošius, Sokolovskij 2009), gaseous biofuels (Kovács, Meggyes 2009; Kovács et al. 2008), hydrogen (Szwaja 2009) or reclaiming energy from exhaust gases. The properties of biofuels and their effects on pollutant formation, along with an increase in the overall efficiency of road vehicles, are among the key aspects of research on pollution control over the transport sector and refer to the following and perhaps other articles (Raslavičius, Bazaras 2010a, 2010 b). There are some fields, for example suspension that is rarely utilized in road vehicles, for energy production.

One of the main trends towards producing vehicles nowadays is developing and correcting vehicle convenience with increased safety. One of the segments is suspension, since it can ensure necessary conditions for other safety systems like ABS, ESP, steering system etc. The suspension has to simultaneously hold the body of the vehicle in comfort which is a difficult problem to be solved. Nowadays, passive suspension systems cannot fulfil conflicting requirements anymore, and thus it becomes more urgent to introduce active and semi-active suspensions in practical use. A direct contact with other safety systems makes the suspension a justified part of the X-by-wire system. This way we can include more functionality in the suspension, since we can access additional information for being used as input data for the active suspension system.

A permanent magnet synchronous tubular (TLSM) machine - used as a motor - is capable of acting as an active element in the suspension (axle displacement, vehicle tilting). When used as a generator, there is no energy consumption of the machine itself; it is also capable of acting as a semi-active element. Proper electronic control allows continuously variable acting force between $F_{\min }(\sim 0 \mathrm{~N})$ and $F_{\text {max }}$, which is covered by switching stator windings between a short-circuit and an opencircuit. When used in a generator's mode, such configuration produces electrical energy that may be dissipated or recuperated for the vehicle power network. By storing this energy via charging batteries, in the same time, the tubular generator behaves as an actuator. The acting force of such a motor depends mostly on the geometry and saturation value of the material used for construct- 
ing the stator. This paper introduces the geometry optimizing method. The input parameters of the performed calculations are the diameter and length of the shock absorber and magnetic properties of the used materials. A prototype model was manufactured and measured in a test-rig. Measurements are used for the validation of calculating the model that includes a magnetic field, induced current and acting magnetic force calculation by moving the piston inside the stator of the machine. The magnetic field is calculated using finite element modelling. Calculations were implemented in MATLAB and Maple programming environments. Optimization has shown that several kN's of reacting force can be reached for a shock-absorber having dimensions similar to conventional design at a piston speed of $0.5 \mathrm{~m} / \mathrm{s}$. Optimal geometry is affected by some other, such as economical or weight-reduction aspects (Wang et al. 1999; Suda et al. 2004; Paz 2004).

This research and development project was Ph.D. work (Zador 2009) done at the Faculty of Electrical Energetic of the Technical and Economical University of Budapest, and was financed, as a pre-development project, by Knorr-Bremse R\&D Centre Budapest.

\section{Shock Absorbers}

The latest models of vehicles are equipped with an extended range of actuators, sensors and software controlling dynamics. For a suspension system, simultaneously holding the body of the car in comfort and meeting requirements imposed for other safety systems like ABS, ESP, steer-by-wire etc. is still a difficult task and a problem to be solved.

In recently produced vehicles, shock-energy is converted into heat employing a hydraulic shock absorber having reacting not controllable force. Furthermore, reacting force depends on the direction the piston moves at and on the speed of displacement. At a piston speed of $1 \mathrm{~m} / \mathrm{sec}$, the maximum value is approximately $3500 \mathrm{~N}$. Controllable suspension systems of a vehicle are semiactive and active suspensions. In the case of semi-active shock absorbers, a control algorithm is needed. Due to the efficiency of electronic, reacting force will be lower but possible to control. The application of semi-active shock absorbers increases passenger comfort, stability, road protection as well as protection for fragile goods. Meanwhile, active shock absorbers (work as an actuator) have the feature of applying greater reacting forces in the suspension than those of a conventional system. They are more suitable for carrying out the above-mentioned functionalities, especially for stability. It is possible for active shock absorbers to apply forces opposite to the force of the spring element in a suspension (Goldner et al. 2001).

\section{PM Tube Generator}

The stator in tubular motors usually has 3-stage windings placed between iron rings, and the piston has permanent magnets applied on it. As an electric motor, a tubular linear synchronous machine (LSM) is capable of acting both as a motor and as a generator. When apply- ing 3-stage sinusoidal excitation on the stator, the piston moves along the tube with a speed depending on the frequency of excitation. When used as a generator, moving the piston induces voltage in the stator windings. The peak value of the induced voltage is proportional to the speed of the piston, the flux density of the pole and the air gap. In both cases, the reacting force of a tubular LSM depends on magnetic parameters such as air gap flux density, magnet volume etc. as well as on geometrical parameters. As mentioned before, there are many types of shock-absorbers as for control medium and the physical principle of work. This research focuses on an electromagnetic shock absorber due to its advantage compared to other absorbers used in such fields as energy management. The majority of shock absorbers are not provided a possibility of using the produced energy arising from the swinging of the body of the vehicle, because it will be converted into heat, dissipated, and therefore lost. We have found the solution to the problem of meeting the above mentioned requirements for developing a permanent magnet three stage synchronous tubular machine (shown in Fig. 1). Hence, the aim of this paper is to discuss the application of a tubular LSM as a (possibly semi-active) shock absorber in vehicle suspension; henceforth, we discuss the generator mode of the machine.

In this case, the LSM has reacting force without energy intake. According to Lenz's law, as the piston moves inside the tube, variations in the magnetic field of the windings induce voltage. When coils are short-circuited, current begins to flow through the finite resistance of each winding. The peak value of this current depends on the speed of the piston and reacts with the field of permanent magnets. As a result of this reaction, some magnetic force is present, which is opposite to the direction of the speed of the piston. This magnetic force eventually reduces the speed of the piston. If the current flowing in the windings is controlled, reacting force implicitly is also controlled and a semi-active suspension element is created. Instead of dissipating the energy provided by the apparatus, it is plausible to recuperate it into the battery pack of the vehicle. The amount of the total recuperated energy depends on the efficiency of the LSM. The system is also capable of behaving as an active shock absorber when used as a motor receiving energy from the on-board battery pack.

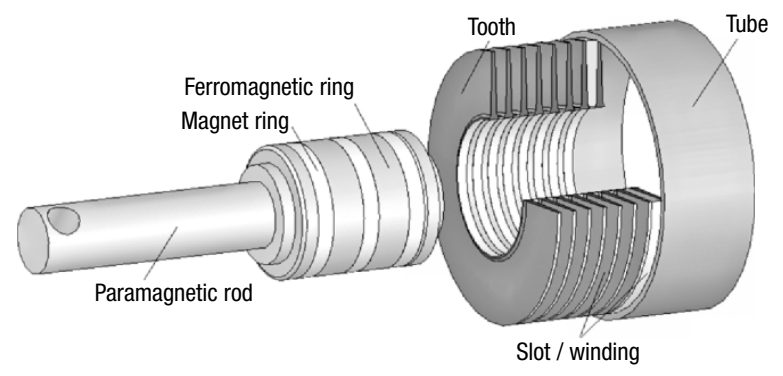

Fig. 1. The build-up of the permanent magnetic shock-absorber (source: own edition) 


\section{Models}

The aim was to create an algorithm for optimizing the geometry of a tubular LSM (Fig. 2) with the fixed diameter and length. The magnitude and level of reacting force as a function of displacement and piston speed were input parameters. The first parameter is the working point of the used neodymium magnet having linear characteristics $\left(B_{r}=1.2 \mathrm{~T} ; H_{c}=840.000 \mathrm{~A} / \mathrm{m}\right)$ at a temperature of $20^{\circ} \mathrm{C}$; thus, the working point depends linear on the resistance of the magnetic circuit and gives maximum energy density if magnets at the points of $0.6 \mathrm{~T}$ and $420000 \mathrm{~A} / \mathrm{m}$ are used. Another parameter was the possible maximum geometry of classical shock absorbers. Other geometrical parameters were calculated analytically from a magnetic circuit model using Maple 9.5 software (Pawluk, Szepanski 1977; Simonyi 2000).

In the magnet-circuit model, the parameters, including the air gap, the radial ratio of the motor and the moving part $\left(r_{\text {rotor }} / r_{\text {stator }}\right)$, the flux density of the pole in the teeth and in the yoke, ferromagnetic material (different $B-H$ curve) and the flux density on the face of the permanent magnet (working point) were systematically changed (Mészáros 2007). A new solution was to analytically calculate the flux between two contra-polar oriented magnet rings (Fig. 3).

The flux that gives pole flux on the surface of the ferromagnetic ring between the magnets depends on the distance of the magnets. There was a parameter giving the quantity of leakage flux density.

This analytical model gives detailed geometrical parameters of the machine where maximum geometry, the

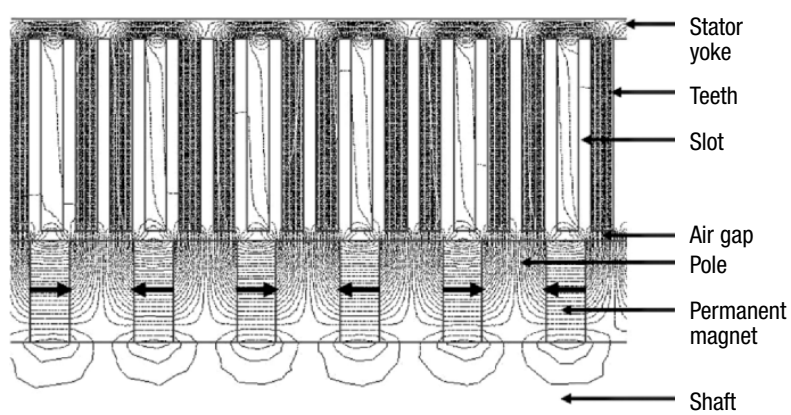

Fig. 2. The cross section of the magnetic field of the tube generator (source: own edition)
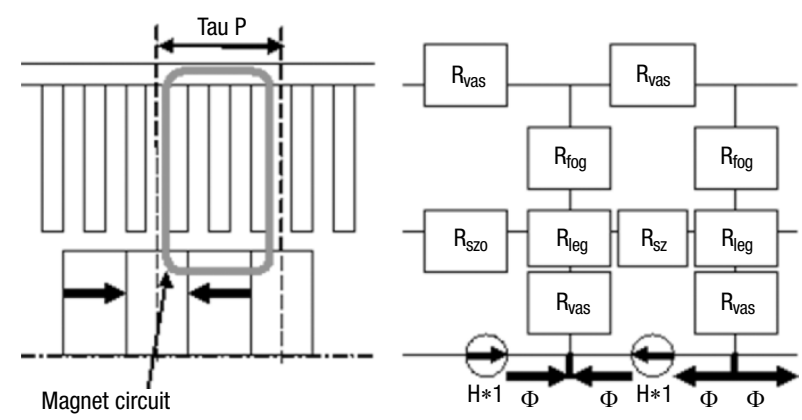

Fig. 3. The magnetic-circuit model of the tubular LSM (Tau P - pole-pitch; $\mathrm{R}$ - magnetic resistance to materials (source: own edition) working point of the magnet and maximum flux density in the ferromagnetic materials were predefined.

Based on the resulting detailed geometrical parameters, the dynamic behaviour of the LSM was simulated applying the finite element method (FEM) and using MatLab 6.5 software. The following simulated parameters were changed:

- piston speed;

- coils in three phases:

- separate in a short circuit;

$\circ$ in the open loop;

- methods of cogging force reduction.

FEM based fix displacement step-size simulation included calculating the number of turns in each slot and flux linkage in the stator (open circuit voltage) at each stage.

The inductance of coils was simulated and calculated employing FEM and leakage flux in the stator at each stage. Regarding the before named parameters, current at every stage was analytically calculated applying $(1) \div(3)$. The current flowing at each stage depends on resistance and inductance values of coils.

$$
\begin{aligned}
& L_{0}=L_{s}+\frac{3}{2} \cdot L_{m} ; \\
& U_{r}=i \cdot R_{0} ; U_{l}=\frac{d i}{d t} \cdot L_{0} ; \\
& U_{m}+U_{r}+U_{l}=0,
\end{aligned}
$$

where: $U_{r}$ is the voltage of the resistance of one-stage windings; $R_{0}$ is the resistance of one stage; $U_{1}$ is the voltage of the inductivity of one stage; $L_{0}$ is the inductivity of one stage; $L_{s}$ is leakage; $L_{m}$ is the inductivity of the main field of the stage; $U_{m}$ is the pole voltage of one stage. If we have all parameters, magnetic force is calculated applying FEM and the Maxwell Stress Tensor method:

$$
F=\frac{1}{\mu_{0}} \oint B_{r} \cdot B_{z} \cdot d A \text {, }
$$

where: $F$ is reaction force; $B_{r}$ is the radial direction of flux density; $B_{z}$ is the axial direction of flux density; $A$ is the surface area in the middle of the air gap.

For the validation of the model, a prototype was constructed. The machine was measured employing a pneumatically operated test rig. Reaction force, current and voltage were measured at a speed of up to $1 \mathrm{~m} / \mathrm{sec}$ of the moving part. The correlation between simulation results and measurement data was about 0.95 and was precise enough to start user-specific optimization based on the created analytical and FE model. During the process, the effect of different input parameters on several output parameters (reacting force, voltage and current) was investigated (Zador et al. 2008).

\section{Special Optimization}

For force optimization, some methods well-known to conventional electrical machine technology and some tubular machine-specific techniques have been applied:

1. Several anti-cogging methods were employed in the simulation environment to optimize the smoothest reacting force as a function of displacement. In ad- 
dition, maximum allowed flux density values in the poles of the piston $\left(B_{\text {pole }}\right)$ and in the teeth of the stator $\left(B_{\text {teeth }}\right)$ were studied. Output was the mean value of reacting force. Different applied anti-cog techniques such as none, fractional slot, skewed poles were calculated. The skewed-poles are realized to cut the rotor in the middle of those and to put a half of Tau long iron material (ring) inside it. When applying the fraction slot winding method, every slot was extended with a length of Tau / (poles of the rotor $\times 3$ ), where $\mathrm{Tau}$ is the slot pitch. The mean values of force using all techniques were in the range of $+/-5 \%$, thus only the force level was relevant (Simonyi 2000; Mészáros 2007). Next, the most optimal techniques for increasing the reacting force of the machine will be presented.

2. Ring-shaped magnets: The concept is very similar to the solution that uses bulk magnets, keeping in mind installation aspects. Magnet rings are threaded on a paramagnetic rod. Iron between the magnets is also ring-shaped. The diameter of the rod inside the piston is determined by mechanical and magnetic parameters (Liska 1960; Zador et al. 2008).

3. Cross-cutting of the teeth: Although smaller in amplitude, some current flows inside the teeth of the stator. The two ends of each coil inside the slots must be accessible, and the idea of cutting the teeth proves to be a solution to both issues. It provides space for the ends of the coils and also makes the cooling of the machine better (Zador et al. 2008).

4. Flux density inside the teeth: Since the layout of the machine is cylindrical, the cross area of the teeth increases, and therefore flux density decreases. If the axial dimension of the teeth decrease continuously in radial direction, that could be a reasonable way to achieve constant flux density along the teeth, as well as additional space for the coils in each slot. This leads to an increase in the absolute value of reacting force (Zador et al. 2008).

5. The length of the stator: If we use 3 stage windings on the stator side, current will be lower than that with separated coils because of the resistance of phase windings. The piston (moving part) needs a place to move, thus the rotor could be much shorter than the stator. The active area (coils), where induced voltage is higher than $10 \%$ of the peak value, is always next to the moving piston (permanent magnets). Therefore, we have to optimize the length of the stator if we do not want to use separated coils (current proportional to force maximum). We chose a $300 \mathrm{~mm}$ long motor where the moving part is $180 \mathrm{~mm}$, and thus the amplitude is $+/-60 \mathrm{~mm}$. Due to resistance, force proportional to current will be different if we use a 300 or $180 \mathrm{~mm}$ length stator. When employing a $180 \mathrm{~mm}$ stator in the middle position, force will be much higher than the situation with a $300 \mathrm{~mm}$ stator (Zador, Vajda 2007).

6. Heat transient simulation is important for gaining knowledge of how heat is generated, because the pa- rameters of the magnet and ferromagnetic materials depend on temperature. Considering the simulated parameters (current, induction), loss of iron (in the teeth and in the yoke) and cupper (coils) was calculated using (5), (6):

$$
\begin{aligned}
& Q_{\text {copper }}=J^{2} \cdot \rho_{\text {copper }} ; \\
& Q_{\text {ferro }}=p_{0} \cdot \frac{B^{2}}{B_{0}^{2}} \cdot \frac{f^{1.5}}{f_{0}^{1.5}} \cdot \rho_{\text {ferro }},
\end{aligned}
$$

where: $J$ is the current density of the coils, $\rho$ is the specific resistance of material; $P_{0}$ a loss parameter $\left(6.2 \mathrm{~W} / \mathrm{kg}\right.$ ); $B_{0}=1 \mathrm{~T} ; f_{0}=50 \mathrm{~Hz}$ (Liska 1960); $B$ is the induction in the teeth or in the yoke; $f$ is frequency in the teeth or in the yoke.

The carried out simulation indicated that deficiency in iron was smaller than that in copper, and therefore the authors have neglected it below the piston's speed of $0.7 \mathrm{~m} / \mathrm{s}$. These were input parameters for the heat transient FE model using QuickField simulation software. When applying the second prototype built after optimization, platinum resistance was found in one of the stator coils to measure heat by operation. This type of resistance is optimal to measure heat, because the value is proportional to temperature. The measurement was made at a piston speed of $0.5 \mathrm{~m} / \mathrm{s}$ with a short 3 stage circuit. Following validation, it was possible to calculate operation times with reference to different isolation and material parameters which indicates that up to a piston speed of $0.5 \mathrm{~m} / \mathrm{s}$ continual operation causes no problems until $30 \mathrm{~min}$ (Zador, Vajda 2007).

7. If reaction force is not sufficient, a special solution to the problem is achieved. It is possible to use copper rings in the slots next to the coils. The copper ring has very low resistance, so the current inside will be stronger. It gives greater reaction force that can be hardly controllable. Two typical forms of using the ring can be identified: a copper ring beneath the coils or in one of the three stages. As regards the coils, it is still possible to control reaction force and recuperate oscillation energy. As shown in Fig. 4, the controlled area is different if we use 3 stage windings (blue) or copper rings in one of the three stages (red) (Zador, Vajda 2007).

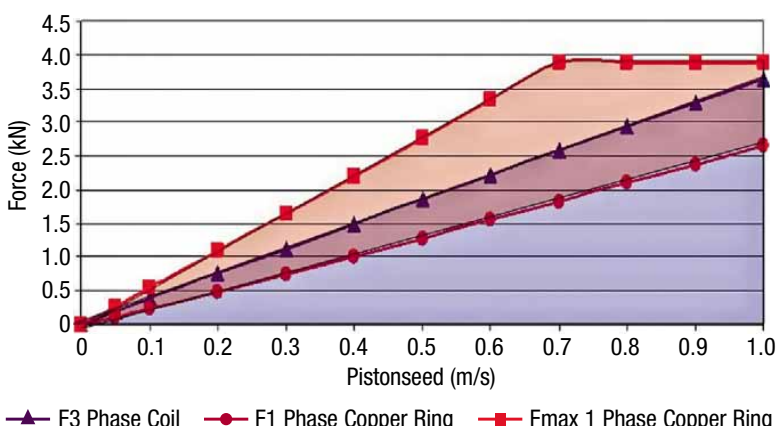

Fig. 4. Characteristics of using the copper ring (source: own edition) 


\section{Control Principle}

This section deals mainly with how to achieve various reacting force characteristics by applying proper control techniques when using the machine as a generator. The system also provides energy during operation. Since induced voltage has constant amplitude at a fixed piston speed, current may be controlled by inserting variable resistance (semi-active suspension control). Energy, in this way, is dissipated in resistance and converted into heat. Instead of dissipating energy, it may be loaded back into the vehicle's battery pack, which is attractive technology for vehicle industry. When using such configuration and controlling energy loaded back into the battery, reaction force of the shock-absorber is controlled. The proposed prototype II is a $6 \mathrm{~kW}$ generator that needs fixed control electronics with a rectifier and a battery. If the battery pack is capable of receiving such energy, a part of full energy may be recuperated, which is dependent on the efficiency of control logic, the rectifier and the battery charger. If the battery is fully charged, it is still possible to dissipate energy in resistance. If the board battery is optimal to use the machine as a motor, active suspension control is realized, and we can reach actuator force on suspension as strong as damping force. In hybrid and electric vehicle technologies, the supply of a similar type of energy is preferred.

\section{Conclusion}

The conducted research has shown that the electromagnetic tube motor is applicable as a shock absorber and can provide the same force as conventional types in addition to having widely controllable characteristics. It needs 1.5 times more space than a conventional shock absorber (Fig. 5), although it has several additional benefits. These models (analytical, FEM) provide a possibility of finding the best geometry fitted to the available shock-absorber space, which will give maximum possible reaction force. The best way to minimize cogging force and to optimize the length of the stator has been found. Since it is an electromagnetic machine able to work in generator's mode, it can be also used for energy recuperation and for charging batteries.

The next step is to develop a complex control electronic device able to control the shock-absorber in semiactive mode; additionally, it can be used for charging batteries. Moreover, we want to make a demonstrator for conferences to present such a system in operation. At the moment, we are looking for financial support to carry on these works.

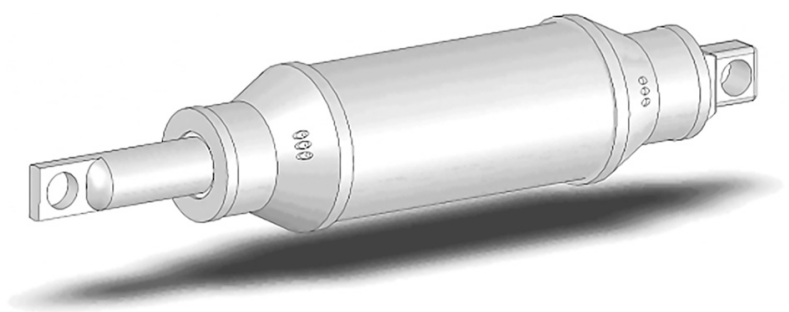

Fig. 5. A possible design of the permanent magnetic shock-absorber

\section{Acknowledgement}

This research paper is a part of the scientific program $D e-$ velopment of Quality-Oriented and Harmonized $R+D+I$ Strategy and Functional Model at BME The project was supported by the New Hungary Development Plan (Project ID: TÁMOP-4.2.1/B-09/1/KMR-2010-0002). This paper is supported by Bólyai János Research fellowship of HAS (Hungarian Academy of Science).

\section{References}

Goldner, R. B.; Zerigian, P.; Hull, J. R. 2001. A preliminary study of energy recovery in vehicles by using regenerative magnetic shock absorber, SAE Technical Paper No 2001-012071. doi:10.4271/2001-01-2071

Kovács, V. B.; Meggyes, A. 2009. Energetic utilisation of pyrolysis gases in IC engine, Acta Polytechnica Hungarica 6(4): 157-172.

Kovács, V. B.; Meggyes, A.; Bereczky, Á. 2008. Investigation of utilization of pyrolysis gases in IC engine, in Proceedings of Sixth Conference on Mechanical Engineering, 29-30 May, 2008, Budapest [CD-ROM].

Liska, J. 1960. Villamos gépek III [Electric machines III]. Tankönyvkiadó, Budapest.

Matijošius, J; Sokolovskij, E. 2009. Research into the quality of fuels and their biocomponents, Transport 24(3): 212-217. doi:10.3846/1648-4142.2009.24.212-217

Mészáros, I. 2007. Development of a novel vibrating sample magnetometer, Materials Science Forum 537-538: 413-418. doi:10.4028/www.scientific.net/MSF.537-538.413

Pawluk, K.; Szepanski, W. 1977. Linearis villamos motorok [Linear electric motors]. Budapest: Muszaki Konyvkiadó (in Hungarian).

Paz, O. D. 2004. Design and performance of electric shock absorber: A Thesis Submitted to the Graduate Faculty of the Louisiana State University and Agricultural and Mechanical College in Partial Fulfillment of the Requirements for the Degree of Master of Science in Electrical Engineering in The Department of Electrical and Computer Engineering. 70 p. Available from Internet: <http://etd.lsu. edu/docs/available/etd-11052004-145157/unrestricted/ Paz_thesis.pdf $>$.

Raslavičius, R.; Bazaras, Ž. 2009. The analysis of the motor characteristics of D-RME-E fuel blend during on-field tests, Transport 24(3): 187-191. doi:10.3846/1648-4142.2009.24.187-191

Raslavičius, R.; Bazaras, Ž. 2010a. Prediction of multi-component effects on ignition delay of oxygenated diesel fuel blends, Indian Journal of Engineering and Materials Sciences 17(4): 243-250.

Raslavičius, R.; Bazaras, Ž. 2010b. Variations in oxygenated blend composition to meet energy and combustion characteristics very similar to the diesel fuel, Fuel Processing Technology 91(9): 1049-1054. doi:10.1016/j.fuproc.2010.03.011

Simonyi, K. 2000. Elméleti villamosságtan [Electromagnetic theory]. Budapest: Muszaki Konyvkiadó (in Hungarian).

Suda, Y.; Shiida, T.; Hio, K.; Kawamoto, J.; Kondo, T.; Yamagata, H. 2004. Study on electromagnetic damper for automobiles with nonlinear damping force characteristics, in The Dynamics of Vehicles on Roads and on Tracks: Proceedings of the 18th IAVSD Symposium Held in Kanagawa, Japan, 24-30 August, 2003, 637-646. 
Szwaja, S. 2009. Hydrogen rich gases combustion in the IC engine, Journal of Kones 16(4): 447-454.

Török, Á. 2009. Theoretical estimation of the environmental impact of biofuel mixtures, Transport 24(1): 26-29. doi:10.3846/1648-4142.2009.24.26-29

Wang, J. Jewell, G. W.; Howe, D. 1999. A general framework for the analysis and design of tubular linear permanent magnet machines, IEEE Transactions on Magnetics 35(3): 1986-2000.

Zador, I. 2009. Rear earth and high temperature superconducting permanent magnet synchronous tube motor/generator optimization for the components of the car suspension system: Thesis of the Ph.D. Work. Budapest: Budapest University of technology and economics. 8 p. Available from Internet: <http://www.omikk.bme.hu/collections/phd/Villamosmernoki_es_Informatikai_Kar/2009/Zador_Istvan/ tezis_eng.pdf $>$.

Zador, I.; Horvath, D.; Vajda, I. 2008. Synchronous tube machine optimization for vehicle shock absorber using permanent or superconducting magnets, in ASC Conference, Chicago, USA, 234-237.

Zador, I.; Vajda, I. 2007. Development of a permanent magnetic semi-active shock-absorber, International Review of Electrical Engineering 2(1): 579-586. 